\title{
Algunas derivas deconstructivas: F. Jameson y Sl. Žižek
}

\author{
Abraham RuBín \\ Proxecto Derriba - Universidade Invisíbel \\ escrituraeimagen@filos.ucm.es \\ Óscar RodRÍGUEZ DE Dios \\ PNPD-FIL/Universidade de Brasilia \\ escrituraeimagen@filos.ucm.es
}

\section{Resumen}

En este texto nos acercamos a las figuras de la herencia y la novedad, siguiendo al propio Derrida en su configuración de las mismas, es decir, siéndole infieles a la herencia para lograr la novedad. Para ello utilizamos cierta lectura de dos pensadores que no acostumbran a hacer deconstrucción y cuyo debate con Derrida -mientras este vivía- fue muy corto, o directamente nulo. Nos referimos a Fredric Jameson y Slavoj Žižek, que en nuestra lectura serán herederos bastardos de cierto discurso deconstructivo o, como diría Derrida, simplemente herederos que se ven envueltos en una deriva deconstructiva.

Palabras clave: herencia, novedad, deriva, Jameson, Žižek.

\begin{abstract}
In this paper we approach the figures of inheritance and novelty, following Derrida's configuration of these two motives, that is, being unloyal to inheritance in order to attain novelty. For this purpose, we use a reading of two thinkers who do not usually do deconstruction and whose debate with Derrida -while he still livedwas scarce or plainly inexistent: Fredric Jameson and Slavoj Žižek. These authors, in our reading, are to be bastard heirs to certain deconstructive discourse, or as Derrida would put it, simply heirs caught up in a deconstructive drift.
\end{abstract}

Key words: Inheritance, novelty, drift, Jameson, Žižek. 


\section{$1^{a}$ parte: F. Jameson}

Como telón de fondo en este texto estará la novedad, especialmente bajo la figura del acontecimiento. Y esto será así por varios motivos: el primero es porque si nos enmarcamos dentro de un coloquio sobre la herencia y Derrida, ésta lleva siempre consigo una transformación que explora la figura de la novedad. También influye porque intentaremos hablar aquí de la postmodernidad como una época de parálisis en la que lo que comienza a tornarse como imprescindible debería ser la llegada de una novedad. Asimismo, y como hablaremos en breve de Fredric Jameson, porque creemos que es el resorte de la novedad lo que, en nuestra lectura, a él no le permitirá salir de una "clausura ideológica y dialéctica" en la que se mantiene encerrado a pesar de sus múltiples tentativas por rehabilitar la imaginación. Y también porque es uno de los motivos fundamentales por los que una lectura deconstructiva puede tener aquí sentido, pues la deconstrucción en general y Derrida en particular, como decíamos, sí permiten un mecanismo que dé lugar al surgimiento de la novedad.

Nosotros llamaremos "postmodernidad" a esta época porque concordamos con Jameson -y con Ripalda- en las características que hacen que ésta se separe de la modernidad. Pero un matiz fundamental a este respecto es que esa separación no viene dada por un corte abrupto, ya que la cultura postmoderna no se rige por innovaciones radicales con respecto al modernismo sino más bien por su manera de tratar la herencia que reciben y su manera de repetirla, su manera de hacerse cargo de ella.

La postmodernidad, pues, no innova radicalmente «ni cancela el proyecto moderno, sino que procede más bien de la experiencia de sus límites» ${ }^{1}$. Quizás el asunto sea que aquello que surge en un límite no es exactamente igual a lo que el límite contiene, ni tampoco es exactamente igual a lo que desborda el límite. Andar por el límite posiblemente desplace al mismo y lo transforme en un umbral. Y el umbral no es aquello que se mantiene dentro de la frontera, tampoco lo que está más allá de ella. El umbral está contaminado por ambos polos, el umbral es inhabitable e indecidible.

Andar por el umbral tendría más semejanza con una experiencia de lo neutro, entendido éste como lo que no es $n i$ una cosa $n i$ otra, como aquello que por contaminado se salva de la identificación pura: a veces $n i$ esto $n i$ aquello, otras veces esto $y$ aquello.

Pretendemos creer que la postmodernidad es algo así como este andar por el umbral, aquello desplazado y, por lo tanto, desfigurado, de los conceptos modernos e ilustrados; la transformación por sí misma de los umbrales en la continua deconstrucción de la(s) frontera(s).

Pero es en Louis Marin donde lo neutro aparece desarrollado con todas sus

1 Ripalda, J. M.: De Angelis. Madrid: Trotta, 1996, p. 60. 
implicaciones ${ }^{2}$. Para Marin es la utopía en sí misma (u-topos) la que marca una negación de principio - anterior pues a toda posición, a todo juicio- que hace que ésta no pueda cumplir su función negadora, sino que se sitúe en medio de la afirmación y la negación, dando lugar a un espacio que no es $n i$ verdadero $n i$ falso: lo $n e u$ tro. De esta manera lo neutro separa los contradictorios y abre un espacio que el discurso no puede tematizar ni hacer suyo. Es un espacio suplementario, donde lo neutro es la potencia productora que permite una brecha, una distancia que quiebra las contigüidades y contradicciones, en la que se alza la alteridad antes de ser inmovilizada en la figura del discurso, en este caso, en la figura utópica.

Es decir, la utopía ocultará este movimiento pues en sí mismo es insostenible; la posición de suplemento impide que pueda tener lugar porque si lo tuviese sería algo sintético, una mediación lógica entre contradictorios. Aquí, el discurso utópico ocupa -en el plano del concepto- lo inabarcable teóricamente, pues, como diría Jameson, está bloqueado por la imposibilidad de salir de la cerrazón ideológica del sistema semiótico de lenguaje y del modo de producción. Está, así, reemplazando lo neutro como suplemento, de ahí que la figura utópica quede apresada ideológicamente en la representación que hace mientras funciona en su discurso como fuerza crítica.

La utopía, de este modo, da lugar, es la casilla vacía que pone en funcionamiento la máquina del sentido, como la khôra en Derrida:

Khôra, ese lugar, ese espaciamiento que se sustrae a los géneros establecidos $y$ destroza la estabilidad de los textos del mismo Platón; ya que khôra, en donde se sostiene el Demiurgo, es aporética y da lugar sin dar realmente nada, simplemente es algo que sucede, como el acontecimiento.

Según Derrida «unas veces khôra parece no ser ni esto ni aquello, otras veces a la vez esto y aquello» ${ }^{3}$.

Khôra es el lugar desde donde el Demiurgo imprime las imágenes de las Ideas, es decir, es lo que recibe todas las determinaciones que hay. Tal vez, por recibir todas las determinaciones, por darles lugar, ella no posee ninguna propia. Como máximo nos podremos aproximar a que es un (no)lugar que da lugar, que introduce a la realidad, un im-posible que introduce a lo posible, es su experiencia la que constituye lo posible. Sirva como penúltimo matiz que este dar lugar «no reenvía al gesto de un sujeto dador, soporte $\mathrm{u}$ origen de algo que llegaría a ser dado a alguien» 4 .

\footnotetext{
2 Marin, L.: Utópicas. Juegos de espacios. Madrid: S. XXI, 1975. Jameson realiza una lectura atenta de esto en "Of islands and trenches", en The Ideology of Theory. Essays 1971-1986. Vol. 11 "Situations of Theory". University of Minnesota Press, 1988.

3 Derrida, J.: Khôra. Trad. cast. de Diego Tatián. Córdoba: Alción Editora, 1995, p. 13.

${ }^{4}$ Op. cit. p. 31.
} 
Si hablamos de un lugar, Derrida siempre va a apuntar hacia aquí, hacia un lugar infigurable, un acontecimiento como aquello que más hondamente nos constituye, aquello que nos da posibilidad, aquello que es real aquí y ahora. Quede claro pues que si hablamos de la acogida a aquel(lo) que viene y de la posibilidad propiamente imposible de recibir la singularidad irreductible de una diferencia inasimilable, hablamos de algo que no puede hacer un sujeto y, sin embargo, es lo que le da la posibilidad de ser a cualquier sujeto.

Marin nos dice que «lo neutro es intransitivo» ${ }^{5}$, lo que nos lleva a ver su irrupción como una acción pura, es decir, indeterminada, sin sujeto ni objeto: un acontecimiento, «como si lo neutro fuese no sólo otro lugar (ni lo uno ni lo otro), sino también lo otro del lugar (el no lugar, la utopía)» 6 .

Pero a Jameson no le interesa esto en abstracto sino como título de una serie de experiencias latentes o patentes por todo el mundo. En este caso la vivencia de realidades contradictorias, y la nueva concepción espacial en la que se pierden las subjetividades postmodernas, el pastiche, en el que el espacio deviene tan abstracto y desubicado como una habitación de una cadena de moteles o una terminal de aeropuerto, un espacio anónimo, que en este caso tiene sentido denominar no-lugar, pues su entorno es tal que ni las cosas ni las personas encuentran su "lugar".

Jameson utiliza el diagrama de Greimas para estudiar cómo lo neutro podría verse en relación con una totalidad cuyas partes se hallan en oposición, pero teniendo como característica el mantenerse fuera de esta totalidad, como diferencia respecto a la diferencia interna de esta totalidad, una diferencia que se añade -tal es el suplemento- al sistema cerrado de las diferencias lógicas. Sería el tránsito entre un contrario y otro, lo que ya no es uno ni todavía lo otro, un lugar vacío que deja sitio al porvenir. En palabras de Jameson, «la fundación de la utopía constituye el acontecimiento supremo, si no el último» 7 , un futuro de perturbación en el que se rompa con el futuro predicho y colonizado, que no es más que una prolongación de nuestro presente. Así se abre un espacio en el que pueda entrar una utopía no anunciada ni preparada de antemano, es decir, un acontecimiento.

Por ello, para salir de la uniformidad (y) del futuro debemos abrirnos a lo porvenir, pues el por-venir no tiene lazos de continuidad sino que es (lo) que llega, lo que ya está llegando desde otra concepción espacio-temporal, lo que rompe definitivamente con las categorías del presente. El porvenir, entonces, no puede sino sorprender, al ser lo desconocido. Como diría Paco Vidarte: una alteridad radical. El porvenir no opera a partir de lo ya fabricado, y al romper con lo prefabricado, con lo uniforme, con lo homogéneo, también rompe con la parálisis del presente.

\footnotetext{
5 Marin, L.: Utópicas. Juegos de espacios. Op. cit. p. 18.

6 Op. cit. p. 19.

7 Jameson, F.: Archaeologies of the future. London-New York: Verso, 2005, p. 231.
} 
Aunque para Jameson esta parálisis del presente es consecuencia del hecho de no poder historizarlo. La concepción histórica que se desprende de aquí no es asimilar la Historia como un texto, narración o referente, sino el hecho de que nos es inaccesible salvo en forma textual y que para abordarla debemos, pues, narrativizarla en el inconsciente político de todo texto. Y para acceder al inconsciente político de un texto y a las coordenadas que éste se esfuerza por reprimir, Jameson utilizará de nuevo la semiótica de A. J. Greimas.

Las estructuras de Greimas esquematizan lo que él cree que es la estructura última de la realidad en un sentido lógico, es decir, sus categorías lógicas ("estructura elemental de significación"), pues para él un relato puede modelarse como una oración individual. El esquema basado en cuatro niveles tiene, además, paralelismo estructural y se basa en oposiciones binarias que completan el recorrido lógico que puede tener un concepto o una relación conceptual de dos elementos.

Pero lo interesante para Jameson es salir de lo que es un esquema estático, transhistórico, y utilizarlo como un punto de partida metodológico que podamos utilizar para una crítica historizadora y dialéctica que nos muestre qué es exactamente una "clausura ideológica". De este modo, podrá analizarse un texto con respecto a sus posibles complicaciones semánticas y/o ideológicas, es decir, intentar llegar a un modelo sobre la conciencia ideológica que se muestra en un texto y cómo ella no podrá salir de los puntos conceptuales que marca el modelo semiótico aunque trate insistentemente de controlarlos o fijarlos, es decir, reprimirlos. Estos puntos nodales no han sido realizados en la lógica de la narración del texto, no se han resuelto $\mathrm{y}$, por tanto, permiten que se puedan leer como aquello que el texto ha reprimido. De este modo se forma una relación fuerte de tensión presencia-ausencia que se dirige hacia lo impensado y lo no-dicho, es decir, hacia el inconsciente político del texto (como vemos, esta es una concepción deudora de la hermenéutica clásica, lo que hace que se separe radicalmente, en este punto, de toda deconstrucción).

El concepto dialéctico que está siempre operando en Jameson asume que la relación entre dos términos antinómicos tiene como telón de fondo fundamental un tercer término, que está siempre ausente y que no es representable, que es la historia misma. Dicho de otra forma, la antinomia conceptual expresa -en la forma de una clausura ideológica- una contradicción social concreta.

Este acontecimiento presente-ausente deja una ranura vacía que no se puede llenar, es decir, el acontecimiento no puede narrarse sino como aporía alrededor de la cual gira la narración, sin incorporarla nunca del todo en su propia estructura. Así, tal vez, al tratar de demostrar la imposibilidad de tal representación, el objeto histórico mismo queda inscrito en el texto.

Ahora bien, el caso es que de la clausura ideológica Jameson no puede salir y no tiene mecanismos para inventar una nueva forma de pensar, del mismo modo que no nos podemos imaginar sin lenguaje o con otro lenguaje, pues es éste el que marca 
las coordenadas en las que somos y estamos (prison-house of language), del mismo modo que nuestra posición de clase implica todo nuestro acercamiento a la realidad y no nos permite que nuestra imaginación se libere de ella. Por eso una solución al encadenamiento conceptual en el que estamos es propiamente inimaginable y no conceptualizable ni representable.

Un acontecimiento tal no se puede preparar y simplemente es rastreado en la obra de Jameson mediante lo que llamamos aquí acontecimiento utópico, imaginado en la novela utópica y la ciencia-ficción contemporánea mediante el acentuamiento, prolongación o doblez de las tendencias actuales que vivimos. Esto debe entenderse bien: no se está anticipando un acontecimiento que nos saque de nuestro encadenamiento mental, se están mostrando las implicaciones que lleva el imaginarse posibilidades consecuentes con las tendencias más inquietantes de nuestra realidad actual.

Es decir, la utopía «puede servir para el negativo propósito de hacernos más conscientes sobre nuestro aprisionamiento mental e ideológico» 8 , pues el futuro se articula allí donde está aquello irrepresentable. Esta incapacidad de imaginar el cambio es también una alegoría de este dilema: la identidad de un presente en el que el deseo está bloqueado y que se enfrenta a la diferencia misma e impensable de un futuro imposible.

En un ámbito más general, pues, el proceso utópico sería una especie de deseo del deseo, un aprendizaje del deseo en un momento histórico en el que todo se le ha puesto disponible al consumidor $\mathrm{y}$, con ello, se ha atrofiado su propia capacidad de desear.

Nuestra situación utópica ahora viene a ser que deseamos el deseo, aquello que se nos ha imposibilitado desde este momento del Capitalismo, aquello que tal vez ya no sea manifestable sino como síntoma.

Para ver, a modo ilustrativo, cómo trata el texto utópico (en este caso de ciencia-ficción) el llamado "cumplimiento del deseo", Jameson cita la novela Picnic en el camino de los hermanos Strugatsky y su espacio de alteridad llamado La Zona. Allí aparecen objetos de todo tipo, algunos con gran valor (por ejemplo baterías que nunca se descargan), otros simplemente desconocidos (y algunos mortales). Esta colección de objetos incomprensibles forman parte de los restos de una actividad extraterrestre (un picnic), y nos sirve para comprobar que solamente podemos categorizarlos bajo nuestras oposiciones binarias de bueno-malo, incluyendo el gran objeto de La Zona, una esfera dorada que concede los deseos humanos. Lo importante es que todos estos objetos son rastros del placer alien, sobrehumano (o extrahumano), aquello que no podemos imaginar.

Por el otro lado, lo que nos queda es potenciar la imaginación y rehabilitarla junto con el deseo, aquello que nos puede servir como adalid para salir de nuestra

\footnotetext{
8 Jameson, F.: Archaeologies of the future. Op. cit. p. XIII.
} 
parálisis. Serán la utopía, el pensamiento utópico en general y la ciencia-ficción contemporánea en particular los encargados de ayudar a rehabilitar la atrofia de nuestros músculos.

La utopía evocará la concepción de alteridad, representando así lo otro del capitalismo. Literalmente, para Jameson «la forma utópica es en sí misma una meditación representacional de la diferencia radical, alteridad radical»9.

El caso es que la utopía nos presenta de nuevo la categoría de la totalidad, presentando en su realización un cierre categorial que da lugar a un sistema que, a su vez, expresa la posibilidad de un enfrentamiento con la alteridad radical. Es clásico el caso utópico del "placer de la construcción", la construcción de la organización política que se lleva a cabo en los textos utópicos y que para Jameson es un ejemplo estupendo de trabajo no alienado y producción. Pero, quizá, lo más interesante de estas construcciones es el ver que nunca se llegan a terminar adecuadamente, como si siempre sobrase o faltase una pieza. Este desajuste que acompaña a toda tentativa de imaginarse la alteridad sí tiene mucho que ver con la deconstrucción y el desquicie que acompaña a toda apropiación, ya desde la différance.

Pues la différance, como sabemos, produce lo desquiciado, las diferencias, el no encajar las cosas, el desajuste. Sólo en el desajuste es posible que algo acontezca ya que cuando todo está ajustado, acordado y fetén no hay lugar para el acontecimiento ni para que nada suceda. No puede servir esto para realizar o desarrollar un programa de cualquier tipo. La différance lo excede y no se pliega, se abre. Es más una grieta, una falla que da lugar y salida, que acontece, que rompe y destroza lo preestablecido, pues viene como línea de fuga, como resquicio por donde escaparse. Llega a(l) no llegar, arrive à ne pas arriver. Puede ser lo mejor pero también lo peor, ya que tras ella acecha el horror, el mal absoluto, lo monstruoso, lo desconocido.

De esta manera, el porvenir llegado con el acontecimiento será disyunto, desajustado, dislocado, desproporcionado... como el espacio y el tiempo que con él lleguen. Como resulta de todo lo que se efectúa desde la différance, como toda su herencia activa. Pues no se hereda únicamente del pasado; es más, no se hereda en absoluto de aquello que está definitivamente muerto y no puede volver: se hereda, sin embargo, de aquello del pasado que queda todavía por venir. No se hereda de lo cerrado, de lo fetén, del concepto. Se hereda de los restos y despojos, de lo vivo, de la diferencia que se repite, y repitiéndose se desplaza y difiere. Es el modo como la herencia se transforma.

El acontecimiento será, pues, lo radicalmente otro, la alteridad absoluta, pues asedia la presencia rompiendo el ser-presente y las condiciones espacio-temporales físicas, porque es efecto de superficie, un simulacro, porque no es una identidad que se nos opone. No se pueden preparar las condiciones para que se dé el acontecimiento, pues éste lleva consigo sus propias condiciones de inteligibilidad y si pre-

9 Op. cit. p. XII. 
paramos unas concretas, asignamos un lugar y prevemos un tiempo, estamos desarrollando un programa que reducirá aquello que huye del acontecimiento, aquello que escapa a toda apropiación.

Tout autre est tout autre, dice Derrida. Cualquier otro es cualquier otro, todo otro es todo otro, cualquiera es cualquiera. Así leído es una tautología. Pero se puede leer también así. Cualquier otro es radicalmente otro, o Lo radicalmente otro es cualquier otro, cualquiera es radicalmente otro, cualquiera o cualquier cosa es la alteridad radical. No hace falta escribir el Otro con mayúsculas, sino que la alteridad radical habita ya y también en lo más cotidiano.

De este modo, el discurso clásico, metafísico, la creencia en un origen, un sujeto, una conciencia, un horizonte de espera, un querer-decir, una presencia en fin -y todo lo que esto conlleva, claro, a nivel político, económico, social y demás-, esas creencias manejan un resorte que impide la novedad, que homogeniza, que bloquea toda apertura y llegada de acontecimientos, los asimila, los digiere; pero siempre quedan restos, márgenes indigeribles, intraducibles. Tal vez se precise también rastrear los restos de acontecimientos que han sido bloqueados por el sistema metafísico -y capitalista, claro-, pues eso es lo que heredamos hoy, aquello que sirve para iniciar la transformación que toda herencia lleva consigo.

\section{$2^{a}$ parte: La ambigüedad de la herencia: Slavoj Žižek}

Vamos a detenernos ahora en una herencia de Derrida un tanto inesperada. Una herencia que tiene una filiación algo bastarda al provenir de un hijo bastante ilegítimo: Slavoj Žižek. Una herencia realmente ambigua, a juzgar por las declaraciones que el propio Žižek ha realizado al respecto. Lo paradójico de esta relación es que ha combinado, al mismo tiempo, una atención permanente de la obra de Derrida en sus aspectos teóricos, sin que faltara la ocasión para que Žižek pudiera poner en boca de Derrida afirmaciones un tanto banales. De manera recurrente, además, Žižek se ha mostrado especialmente crítico con la recepción de la deconstrucción más allá de Derrida. ¿Cómo explicar esta situación?

Es sobre esta herencia ambigua, paradójica, que vamos a hacer algunas consideraciones, que si bien no van a exponer nada nuevo en lo que a la obra de Derrida se refiere, nos permitirán aclarar ciertos aspectos poco visibles de la filosofía de Žižek, además de situar la cuestión de la herencia de Derrida en relación a la teoría política contemporánea. En cualquier caso, ya podemos adelantar que no hay motivo para la inquietud, pues a pesar de lo que pueda parecer a veces, se trata principalmente de un boxeo de sombra. Žižek combate ante un rival imaginario, lanza provocaciones ante un espejo que sabe que no devolverá el golpe. Un aprendizaje necesario, que quizá sería más apropiado definir como un boxeo espectral, pues no 
ha habido en realidad ningún debate público real entre ambos autores. Puesto que lo que nos interesa es, especialmente, una herencia política vamos a centrarnos en el eje Hegel-Marx, para tratar de valorar en qué medida Žižek toma en consideración la filosofía de Derrida para desplazar su propia herencia teórica.

Comenzando por Hegel, habría que señalar, en primer lugar, un trabajo por parte de Žižek, sobre la relación de la dialéctica y del resto, que podríamos situar como una herencia de Derrida. Sin llevar esta discusión a un análisis textual de los lugares que podrían parecer pertinentes, aquellos en los que Derrida se ha ocupado preferentemente de Hegel, Žižek asume como punto de partida la problemática del resto. ${ }^{10}$ Sin embargo en una forma de proceder típica en él, va a desplazar esa herencia invirtiendo los términos. No se trata de que la dialéctica consista en un proceso inmanente y necesario, que supera toda contradicción sin resto, la versión más o menos usual al respecto de la Aufhebung. Lo importante es que ese resto tiene un carácter radicalmente contingente que es fundamental para el desarrollo lógico de la dialéctica como tal. Es decir, tomando como punto de partida el trabajo de Derrida, considera sin embargo que la cuestión fundamental no reside en la existencia de un resto que es inasimilable para cualquier tipo de operación conceptual.

Hasta aquí podría uno estar más o menos de acuerdo con Žižek, sin embargo en uno de sus primeros textos añade una afirmación de una manera pretendidamente provocativa: en lo que respecta a Hegel, dice "Derrida tumba una puerta abierta".11 Lo injustificado de esta afirmación, parece quedar más claro una vez que se sigue la línea argumental del propio Žižek. Aunque no hemos de detenernos ahora en esta cuestión, sería más adecuado señalar que Žižek más bien ha franqueado una puerta que Derrida (quizá entre otros) le ha abierto. Habría que decir, al menos, que Glas ha llevado a cabo un trabajo sobre la monumentalidad de Hegel imprescindible para poder volver a transitar por ese sendero. ¿Qué se propone entonces con semejante declaración? Pues toda esta trifulca tiene, en realidad, mucho que ver con la sutileza de una operación que quiere transitar entre la lectura popular de manual de Hegel, (recordemos la vieja tesis-antítesis-síntesis), cierta lectura estándar que se ha instalado en el Hegel más académico y salir al paso de la aproximación a Hegel desde alguna lectura epigonal de Derrida. ${ }^{12}$ Žižek quiere dar, a su manera, un paso más allá, extendiendo no sólo a toda la tradición, sino hasta al propio Hegel, la

\footnotetext{
10 Sin entrar en la cuestión de la transversalidad del tema en la obra de Derrida, resultaría imprescindible al menos referirse a Glas, Paris: Galilée, 1978. Para el enfoque que aquí adoptamos el trabajo económico sobre Hegel es también muy señalado en el texto "De la economía restringida a la economía general. Un hegelianismo sin reserva”, en Derrida, J. (1967) La escritura y la diferencia, trad. del francés Patricio Peñalver, Anthropos: Barcelona, 1989. P. 271-317.

11 Žižek, S. (1991): Porque no saben lo que hacen. El goce como un factor politico, trad. Jorge Piatigorsky, Buenos Aires: Paidós. 1996. P. 91.

12 Cfr. Gasché, Rodolphe (1986): The Tain of the Mirror: Derrida and the Philosophy of Reflection. Harvard University Press, 1986.
} 
misma argumentación. Con ello - y siguiendo una de las líneas fundamentales de su filosofía-, desplaza el eje de toda la tradición del materialismo dialéctico, llegando a señalar que en su lectura de Hegel: "Lenin era secretamente idealista".13

En función de este planteamiento es obvio que Žižek va encontrar una clara afinidad en el planteamiento de fondo entre lo que proponen ambos autores. Podríamos decir que en los numerosos acercamientos que Žižek ha llevado a cabo sobre la obra de Hegel, ha detectado un mismo procedimiento en la dialéctica hegeliana: en ella se lleva a cabo un doble desplazamiento que es inconmensurable como tal. Es decir, se produce, por una parte, un desplazamiento espacial, porque el resto del proceso sólo es perceptible si lo enfrentamos de una forma oblicua, para una mirada directa resulta indistinguible. Por otro lado, este resto sólo existe temporalmente en la forma de un exceso, como una anticipación o una pérdida, nunca en el ahora de un presente pleno. Esa presencia sólo la adquiere retroactivamente, de ahí su radical ambigüedad y la prueba de su imposibilidad. A partir de aquí no es difícil percibir que una de las conclusiones de Žižek será que, en última instancia, tanto el proceso de la diseminación como el de la dialéctica presentan unos recursos más semejantes de lo que se ha querido ver. ${ }^{14}$

Boxeo de sombra, como decíamos, porque es probable que aquello que de entrada se planteaba polémicamente sólo tenga que ver con determinadas políticas de la teoría. También desde luego porque Žižek nunca pertenecería a un club que lo admitiera como socio. Pero dejemos de lado a Hegel, porque este comportamiento paradójico es mucho más perceptible en lo que respecta a la herencia de Marx que Žižek asume abiertamente. Al contrario de lo que sucede con Derrida, Žižek reivindica claramente una herencia de Marx para alejarse al mismo tiempo de lo que habitualmente se entiende en esos términos.

Desde una herencia marxista los Cultural Studies parecen haber recogido el testigo de la teoría crítica, especialmente en el ámbito anglosajón, en lo que refiere una labor teórica que mantiene su frente abierto en la crítica a los procesos culturales de las sociedades de consumo. Žižek, por estilo y por inclinación, parece converger con este tipo de corriente, sin embargo desde hace algunos años insiste en desvincularse de este tipo de estudios, a la vez que amplia su crítica a la izquierda que se reclama, en estos tiempos, como una herencia del marxismo. Desde finales de los años 90 Žižek ha tratado de anticiparse de algún modo a ese viaje. Una de sus tesis principales desde entonces ha sido que: "La principal característica de la era pospolítica contemporánea del final de las ideologías es, reiterémoslo, la despolitización de la esfera de la economía."15 Ha proclamado, en definitiva, la necesidad de

13 Žižek (2002): A propósito de Lenin, trad. del alemán Sebastián Waingarten, Buenos Aires: Atuel/Parusia. 2004. P. 37.

14 Esta discusión se lleva a cabo de manera fundamental en la primera parte de Žižek, S. (1991): Ops. Cit. P. $19-130$ 
repolitizar la esfera de la economía, como algo que dejan al margen los estudios culturales, e incluso la teoría política francesa de izquierda que representan autores como Badiou, Balibar, o Rancière.

Sus argumentos políticos abundan en la necesidad de conducir a la toma de decisiones colectivas más allá de la problemática sobre diferencias culturales, que no llega a alcanzar el nivel fundamental en el que se toman realmente las decisiones. Esta idea, quizá poco más que un lugar común, ha sido acompañada por un trabajo específico sobre las relaciones entre economía y política, que trata de trascender el marco de los estudios culturales, aunque tampoco se trata de un trabajo sobre la economía en un sentido convencional. Además del abandono del ámbito económico por parte de la izquierda, esta línea argumentativa de Žižek toma en consideración el triunfo de la utopía capitalista, y el nuevo escenario global de la escatología del fin de la historia, en los términos en los que ya lo planteaba Espectros de Marx.

Es decir, desde un planteamiento crítico no se trata sólo de la falsedad manifiesta del relato que proclama el triunfo del capitalismo. Esto es, que se siga presentando a sí mismo como una respuesta realista a las necesidades de la gente. A pesar de que sabemos que esa situación no describe la realidad del capitalismo, la dinámica capitalista parece triunfar simplemente de un modo espontáneo. Y es en clara alusión a este hecho que Žižek, en un texto de hace una década, vuelve a plantear una argumentación de manera provocativa en relación a Derrida: Si la espectralidad es irreductible, a pesar incluso de Marx, dice Žižek "¿no es la conclusión de Derrida (en Espectros de Marx) que el Capital es Différance, un movimiento que no llega nunca a su fin, al círculo perfecto de su circulación, al ajuste final de cuentas, y que siempre difiere?". ${ }^{16}$ En la respuesta a esta pregunta que, más que nada, Žižek se dirige a sí mismo, ha venido trabajando desde entonces. $Y$ en un procedimiento típico de su forma de trabajar similar al que ha empleado con el tema del resto hegeliano, Žižek no va buscar directamente en la obra Derrida las posibles respuestas. Ya en el contexto de la cita anterior nos encontramos a su interlocutor privilegiado para esta temática: Kojin Karatani.

Según Žižek, Karatani en una obra de 1995, La arquitectura como metáfora: "muestra como el capitalismo es ya su propia deconstrucción, un sistema inestable que se mantiene gracias a una revolución ininterrumpida, cuya inestabilidad es su auténtico motor". ${ }^{17}$ Aunque esto más que plantear una solución es sólo el enunciado del problema. Uno de los problemas para una economía general. Pues bien, esta herencia de Marx, que a su vez es una herencia de Derrida, es lo que de algún modo

15 Žižek (1999): El espinoso sujeto. El centro ausente de la ontología política, trad. Jorge Piatigorsky. Barcelona: Paidós. 2001. P. 376.

16 Žižek (2002): Ops. Cit. P. 110.

17 Karatani, K. (1995): Architecture as Metaphor. Cambridge, MA: MIT Press. P. 117 
se traen entre manos tanto Žižek como Karatani. Ambos han retomado esta cuestión en dos obras relativamente recientes en las que nos vamos a detener un momento.

Más concretamente, este motivo de la circulación desenfrenada y autónoma del capital a escala planetaria global ha conducido a ambos autores a reconstruir de algún modo el planteamiento de Marx sobre la teoría del valor en el fetichismo de la mercancía. No sólo en lo que respecta al ámbito de la producción sino, especialmente, al ámbito de la circulación. Ya Derrida había señalado en Espectros de Marx, que la forma-mercancía se aparece como algo previo al propio valor de uso. 18 De hecho subraya que la espectralidad de la forma-mercancía es algo presente ya en el valor de uso, tal y como lo presenta la puesta en escena previa del capítulo inicial sobre la mercancía en El Capital. Y esto además frente a los intentos fracasados de Marx para reducir el ámbito de la espectralidad, por hacer justo aquello que él mismo le reprochaba a Stirner en La Ideología alemana.

\section{Paralaje: economía y política}

¿Pero es entonces la espectralidad el auténtico motor del capitalismo? Vamos a ver cómo cada uno responde a esta cuestión, a partir de un concepto común: paralaje. Éste es un término que Žižek ha tomado de la obra de Kojin Karatani Transcritique. On Kant and Marx (2003), el cual lo ha empleado en su obra tomándolo a su vez de un fragmento de los Sueños de un visionario de Kant. Žižek comenzó a hablar de paralaje en un artículo de 2004, y le ha dedicado todo el protagonismo en su última gran obra The Parallax View que publicó en 2006. 19

El punto de partida además es también muy semejante en ambos autores que evalúan el proyecto de Marx, y específicamente la teoría del valor, en función de la relación entre los Grundrisse y El Capital. 20 Karatani, en primer lugar, considera que el elemento fundamental que no hay que perder de vista se encuentra en la circulación del valor como mercancía. Y en este sentido afirma que el Capital deja probado el hecho de que la plusvalía se realiza plenamente en la circulación. Es decir, el elemento fundamental del proceso es la distancia temporal que media entre la producción del valor y su circulación hasta ser vendida como mercancía. Precisando más, indicará incluso que el momento clave para la explotación de la plusvalía se produce cuando los trabajadores consumen/ compran lo que ellos mis-

18 Derrida, J. (1993): Espectros de Marx. El estado de la deuda, el trabajo de duelo y la nueva internacional, trad. del francés J. M. Alarcón y Cristina de Peretti, Madrid: Trotta. 1995. P. 179.

19 Žižek, S (2004): “The Parallax View” en New Left Review N 25, Jan-Feb 2004. P. 121-134.

20 No vamos a profundizar más aquí en la relación entre los dos textos de Marx, cuestión importante y controvertida que ha conducido a desarrollos divergentes. Tanto Žižek como Karatani aluden a Toni Negri y a Deleuze \& Guattari. 
mos producen. Es decir, cuando aquello que se produce es su propia subjetividad como consumidores, en ese preciso instante se origina un salto en el proceso por el que cual éste se puede cerrar de algún modo. De lo contrario el movimiento tendría que continuar sin otra posibilidad que el desplazamiento indefinido. Karatani centra sus análisis y sus propuestas sobre ese foco que para él representa el momento crítico por el que el capitalismo debe pasar, el lugar imprescindible para cerrar el proceso y en el que todavía es posible cierta autonomía de acción.

Žižek, por su parte, retoma esta idea de Karatani: el proceso por el que una mercancía se vende convirtiéndose en una mercancía no es un desarrollo inmanente del concepto de valor. Pero su idea de la relación entre los Grundrisse y El Capital es otra. Veamos por qué. Para Žižek, los Grundrisse evidencian el fracaso de Marx en su intento por deducir dialécticamente la distinción entre valor de uso/valor de cambio a partir del concepto de Valor. En ellos se describe a un sujeto revolucionario que trata de apropiarse de su contenido social alienado y al capital como la sustancia alienada. En El Capital, sin embargo, Žižek considera que el punto de partida de Marx es ya la dualidad del concepto de Valor: valor de uso/valor de cambio. Es decir el movimiento que describe El Capital es análogo al movimiento hegeliano de la sustancia/sujeto, un movimiento circular que no se alcanza a sí mismo. Y esto sucede en el caso de la descripción de Marx, porque además Žižek entiende que ya ha demostrado que la circulación inmanente tampoco coincide con la dialéctica de Hegel, comos hemos mencionado al principio. Esta idea de la vinculación de Hegel con Marx, a través de la interpretación de El Capital, a partir de la lógica de Hegel, es uno de los núcleos fundamentales de la obra de Žižek. Es por tanto el espectro de Hegel, más que el de Marx, el que aquí desempeña un papel fundamental. A pesar, por tanto, de que la exposición de Marx del movimiento del capital utilice una terminología hegeliana, está lejos de la idea del desarrollo circular del Espiritu hegeliano tal y como esta se entiende usualmente. Tanto la Lógica de Hegel como el Capital de Marx exponen un movimiento que nunca se alcanza a sí mismo, que nunca repone el crédito que se otorga: su funcionamiento se basa en un "como si", en una ficción contrafáctica, pero que es de algún modo productiva. ¿Cómo explicar esta situación? ¿Es entonces el capital el verdadero sujeto/sustancia? se pregunta Žižek: "Sí y no", responde. "Para Marx, este movimiento circular que se engendra a sí mismo es precisamente la fantasía inconsciente del capitalista que parasita al proletariado como la pura subjetividad sin sustancia." 21

La argumentación de Žižek se desarrolla en tres niveles:

- En un primer nivel el capitalismo construye una ficción, que simplemente se impugna en su confrontación con la realidad. Es decir, es preciso negar esta ficción por la experiencia cotidiana de que el objetivo de la circulación del capital NO es la

21 Cfr. Žižek, S (2002): Ops. Cit. P.115; Žižek, S. (2006a): Visión de Paralaje. trad. Marcos Meyer, Buenos Aires: F.C.E. P. 101; Žižek, S. (2006b): The Parallax View Cambridge, MA: MIT Press. P. 60. 
satisfacción creciente de las necesidades humanas. En segundo lugar, hay que señalar que esta ficción tampoco es la realidad del capitalismo pues el capital no se engendra a sí mismo, sino que depende de la generación de plusvalía que explota del obrero.

- Hasta aquí, sin embargo, no se ha alcanzado el nivel de la fantasía: Para Žižek es además imprescindible agregar un tercer nivel a esta oposición entre la experiencia subjetiva del capitalismo como instrumento de satisfacción y la realidad social objetiva de la explotación: "el engaño objetivo, la fantasía inconsciente denegada del misterioso movimiento circular inmanente que genera el capital, es la verdad (aunque no la realidad) del proceso capitalista."22

- Esta fantasía inconsciente, que estructura el universo capitalista, la forma-mercancía dicho en los términos de Marx, es la que pone en evidencia la existencia de un vacío fundamental, es el síntoma que permite postular un límite a la danza inmanente del capital por el cual éste provee las condiciones críticas para su propio colapso. La única manera, por lo tanto, "de formular la verdad del capital es liberar a esta ficción de su movimiento inmaculado y de su generación inmanente."23 Finalmente es entonces que nos encontramos de nuevo con la idea de paralaje, pues si la fantasía del capital, su verdadera ficción es la circulación inmanente, y al mismo tiempo su realidad es la explotación de la producción, esto es debido a que la relación entre producción y circulación es una relación de paralaje.

De manera general, Žižek considera que la brecha (gap/béance) de paralaje es "la confrontación de dos perspectivas estrechamente vinculadas entre las cuales no es posible ningún campo neutral en común". Es decir, la brecha de paralaje es una relación entre dos ámbitos en los que se produce una diferencia mínima que no se deriva de ninguna de sus propiedades positivas. Además esta noción de brecha de paralaje es la clave necesaria que permite discernir el núcleo subversivo de la dialéctica, y recuperar la filosofía del materialismo dialéctico:

El auténtico problema reside, para el materialismo dialéctico, en comprender la posibilidad del surgimiento de la verdadera distancia entre pensamiento y ser, la negatividad del pensamiento, a partir del mero orden del ser. 24

Žižek asume como una decisión estratégica filosófico-política de su obra The Parallax View, y como una noción fundamental para el materialismo, la designación de esta diferencia mínima que "separa al Uno de sí mismo con el término parala-

22 Žižek, S. (2006b): Ops. Cit. P. 60; Žižek, S (2006a): Ops. Cit. P. 102.

23 Ibid.

24 Žižek, S. (2006b): Ops. Cit. P. 6. 
je"25. Es decir, en concebir la propia relación entre espectralidad y resto como una relación de paralaje. En esta decisión tienen mucho que ver las discusiones que Žižek lleva a cabo en la tercera parte del libro, donde lo que emerge en un primer plano es el paralaje entre la política y la economía. La posibilidad de superar cierto bloqueo político. O cierto planteamiento de la política, en retirada de lo económico. La cuestión es que a pesar de haber una relación mutua entre política y economía, a pesar de su mutua implicación, no puede haber un contacto directo entre ambos campos. No es posible traducir la atención sobre el exceso capitalista y su propia revolución inmanente simplemente en términos de dominación y regulación. La relación entre ambos no es simétrica. Así que tienen que fallar igualmente tanto la reducción de lo político a un mero reflejo de intereses económicos como la reducción de lo económico a una reificación de un proceso político principal. Quedarse con un lado o con el otro, o simplemente con la afirmación de ambos, genera un fetichismo inevitable.

Žižek considera que la fantasía del capitalismo consiste en esa fuga hacia adelante, incesante, pero sólo como una parte de la ficción con que se legitima, pues en la realidad necesita cerrar el proceso, para poder seguir avanzando, para que la plusvalía abandone su ámbito espectral y devenga un beneficio neto, empírico, por encima de cualquier otra consideración. Pero no hace las dos cosas en el mismo momento y en el mismo lugar.

Sobre los motivos que justifican la introducción de este nuevo término, paralaje, Žižek no ofrece más explicaciones. Pero parece que el hecho de que el capitalismo quiera jugar de una forma hipócrita al juego de la différance, hace necesario y urgente volver a plantear esa diferencia mínima, aunque sea al precio de pactar con el diablo de la negatividad. ${ }^{26}$ Un desplazamiento o una impaciencia que denota algo, seguramente un síntoma más de que "the time is out of joint". Aunque, por supuesto, nadie está obligado a seguirlo. En cualquier caso, nada más lejos de la intención de Derrida que patrocinar la recuperación de viejos términos como sujeto, ideología o materialismo. No obstante, y con ello me gustaría concluir, la mejor manera de entender esta idea de paralaje es aplicársela a la obra del propio Žižek.

Si uno busca un principio hermenéutico desde el que explicar su filosofía, un significado, difícilmente encontrará algo que pueda permanecer estable, idéntico a sí mismo. O sólo lo encontrará al precio de realizar una autopsia. De fingir un asesinato, de crear una doctrina.

25 Žižek, S. (2006b): Ops. Cit. P. 7; Žižek, S (2006a): Ops. Cit. P. 16."Puesto que he escrito páginas en las que polemizo con el trabajo de Jacques Derrida, ahora, que la moda derridiana está declinandoes quizás el momento de honrar su memoria señalando la proximidad de esta minimal difference con aquello que él designó como différance, ese neologismo cuya propia notoriedad obstruye su inaudito potencial materialista." Žižek, S. (2006b): Ops. Cit. P. 1

26 Cfr. Žižek, S. (2006c) "A Plea for a Return to Différance (with a Minor Pro Domo Sua)" in Critical Inquiry, Vol. 32; N 2: 226-249. 
El resto que nos quedaría emerge más bien como una variación de motivos, de intuiciones geniales, de argumentaciones confusas, de contradicciones más o menos asumidas, de anécdotas personales, y de análisis más bien peculiares. Pero la suya es también una filosofía que juega en dos tableros. Una filosofía que sólo sabe lo que dice, cuando no dice lo que sabe. La economía de su discurso muestra un trabajo formal sobre la repetición (de temas, de motivos, de obsesiones) que es llevado por su parte a extremos insospechados, realmente difícil de explicar de forma oral.

Hay un trabajo conceptual por su parte sobre el resto, sobre la contingencia, sobre el síntoma y el fantasma, una escatología, en su doble sentido: una fantología (Hantologie), muy singular desde luego. Pero sucede que esta escatología se realiza al mismo tiempo, en el ejercicio de su escritura, en su estilo, en su retórica, en la forma en la que emplea ejemplos de todo tipo para ilustrar la teoría. O dicho con más precisión en la forma en la que emplea teorías de todo tipo para ilustrar sus ejemplos. Žižek se sitúa y nos sitúa en la imposible conjunción de ambos momentos, en la paralaje entre lectura y escritura. Ahí es donde se sitúa preferentemente su herencia de Derrida. Contaminante y contaminada, un poco bastarda, como decía al principio.

$\mathrm{Si}$, finalmente, todo esto les ha parecido prescindible, más que una herencia, un robo o una tergiversación, seguramente están en lo cierto. Se puede escribir algo mucho mejor en apenas diez líneas, y a mí sólo me queda cometer una última imprudencia, al leérselo en voz alta.

En esos casos, pues, muy refinados, la estructura, la construcción (Abbau) del fetiche reposa a la vez sobre la denegación y sobre la afirmación (Behauptung), la aserción o la asunción de la castración. Este a-la-vez, este al-mismo-tiempo de dos contrarios, de dos operaciones opuestas, impide decidir lo indecidible. Constituye una economía de lo indecidible: no que lo indecidible interrumpa allí la eficacia del principio económico. Se pone al servicio de una economía general, cuyo campo es preciso abrir entonces. Hay una especulación económica sobre lo indecidible. No es dialéctica, pero juega con la dialéctica. La ficción consiste en fingir que perdemos, que nos castramos, que nos damos muerte para apartarnos de ella. Pero la ficción no nos aparta de ella. Perdemos desde ambos lados, en ambos registros, para saber jugar en ambos tableros. Bajo esta condición la economía deviene general. ${ }^{27}$

27 Derrida; J. (1974): Ops. Cit. Columna Izqda. P. 235-236. 